\title{
Microstructured Optical Waveguide-Based Endoscopic Probe Coated with Silica Submicron Particles
}

\author{
Timur Ermatov ${ }^{1}$, Yury V. Petrov ${ }^{2}$, Sergei V. German ${ }^{1}$, Anastasia A. Zanishevskaya ${ }^{3}$, \\ Andrey A. Shuvalov ${ }^{3}$, Vsevolod Atkin ${ }^{2}$, Andrey Zakharevich ${ }^{2}$, Boris N. Khlebtsov ${ }^{2,4}{ }^{(\mathbb{C}}$, \\ Julia S. Skibina ${ }^{3}$, Pavel Ginzburg ${ }^{5}$, Roman E. Noskov ${ }^{5}$, Valery V. Tuchin ${ }^{2,6,7}$ \\ and Dmitry A. Gorin 1,* \\ 1 Skolkovo Institute of Science and Technology, 3 Nobelya str., 121205 Moscow, Russia; \\ timur.ermatov@skolkovotech.ru (T.E.); s.german@skoltech.ru (S.V.G.) \\ 2 Department of Physics, Institute of Nanostructures and Biosystems, Saratov State University, 83 \\ Astrakhanskaya str., 410012 Saratov, Russia; welcometospain@mail.ru (Y.V.P.); ceba91@list.ru (V.A.); \\ lab-15@mail.ru (A.Z.); khlebtsov_b@ibppm.ru (B.N.K.); tuchinvv@mail.ru (V.V.T.) \\ 3 SPE LLC Nanostructured Glass Technology, 10150 Let Oktjabrja, 410033 Saratov, Russia; \\ zan-anastasiya@yandex.ru (A.A.Z.); shuvalovaa@nano-galss.ru (A.A.S.); skibinajs@yandex.ru (J.S.S.) \\ 4 Institute of Biochemistry and Physiology of Plants and Microorganisms, 13 Prospekt Entuziastov, \\ 410049 Saratov, Russia \\ 5 Department of Electrical Engineering, Tel Aviv University, Ramat Aviv, Tel Aviv 69978, Israel; \\ pginzburg@post.tau.ac.il (P.G.); nanometa@gmail.com (R.E.N.) \\ 6 Interdisciplinary Laboratory of Biophotonics, Tomsk State University, 36 Lenin's av., 634050 Tomsk, Russia \\ 7 Laboratory of Laser Diagnostics of Technical and Living Systems, Institute of Precision Mechanics and \\ Control of the Russian Academy of Sciences, 24 Rabochaya str., 410028 Saratov, Russia \\ * Correspondence: d.gorin@skoltech.ru; Tel.: +79172077630
}

Received: 5 April 2019; Accepted: 28 April 2019; Published: 1 May 2019

\begin{abstract}
Microstructured optical waveguides (MOW) are of great interest for chemical and biological sensing. Due to the high overlap between a guiding light mode and an analyte filling of one or several fiber capillaries, such systems are able to provide strong sensitivity with respect to variations in the refractive index and the thickness of filling materials. Here, we introduce a novel type of functionalized MOWs whose capillaries are coated by a layer-by-layer (LBL) approach, enabling the alternate deposition of silica particles $\left(\mathrm{SiO}_{2}\right)$ at different diameters- $300 \mathrm{~nm}, 420 \mathrm{~nm}$, and $900 \mathrm{~nm}$-and layers of poly(diallyldimethylammonium chloride) (PDDA). We demonstrate up to three covering bilayers consisting of 300-nm silica particles. Modifications in the MOW transmission spectrum induced by coating are measured and analyzed. The proposed technique of MOW functionalization allows one to reach novel sensing capabilities, including an increase in the effective sensing area and the provision of a convenient scaffold for the attachment of long molecules such as proteins.
\end{abstract}

Keywords: sensing; layer-by-layer deposition; surface modification; microstructured optical waveguide; silica particles

\section{Introduction}

Microstructured optical waveguides (MOWs) have matured into a major area of cutting-edge science since its inception in 1996 [1]. They have found numerous applications in optics and related fields [2], including the production and modification of solar cells [3], biosensors [4-6], biomedical investigation [7-9], endoscopy [10,11], and clinical imaging [12,13]. In combination with graded-index (GRIN) lenses [14,15], MOWs have been employed in optical microscopy $[10,16,17]$ and 
microendoscopy [18]. Hollow capillaries of MOWs (HC-MOWs) filled with fluids offer a powerful playground for in-fiber microfluidic optical sensing, enabling measurements of fluid's refractive index, temperature, fluorescence signals, or biochemical agent concentrations [19]. They are also very prospective for neurophotonics studies and applications, specifically, in the field of optogenetics and monitoring/controlling of the blood-brain barrier [20-26].

Approaches for liquid sensing within MOWs can be subdivided into two categories: the first relies on detecting optical properties of molecules via light absorption [27], fluorescence [28], or Raman scattering [29]. In the solid-core MOWs, light propagates in the core, and the mode evanescent tail probes the optical properties of an analyte in nearby holes.

The second category of MOW-based sensors exploits fiber resonant features that can be very sensitive to variations in the refractive index within the holes. Such resonant features can be caused by either Bragg or long-period gratings [30,31], intermodal interferences, e.g., in tapers [32], surface plasmon resonances [33,34], or the photonic bandgap properties of MOWs themselves [35,36]. HC-MOWs belong to the latter class. Here, the analyte fills one or several fiber capillaries, serving as a part of the probed resonator, and the optical resonances of these fluid-filled channels are probed. The major benefit of using MOWs rather than equivalent techniques based on cuvettes and bulk optics lies in combining the long interaction lengths with strong overlapping between light and the analyte within small sample volumes, giving rise to high sensitivity [37-39].

Importantly, all the previous works on this topic have demonstrated sensing functionalities of MOWs for capillaries with smooth walls [40,41]. The potential of MOWs with porous walls remained obscure. In this work, we develop the technique for HC-MOWs coating with chemically and mechanically stable [42-47] and monodisperse submicron silica particles by the layer-by-layer (LBL) deposition approach [48-53]. We demonstrate up to three covering bilayers consisting of 300-nm, 420-nm, and 900-nm silica particles [54] and poly(diallyldimethylammonium chloride) (PDDA) between them. Submicron silica particles were chosen based on their optical properties and easy, highly monodisperse synthesis. Due to the refractive indexes of silica and the fiber glass being very close, they may provide the porosity of the capillary walls without too substantial rise in the transmission losses, and the monolayer of silica particles can be considered as an effective increase in the capillary wall thickness [55-58]. Modifications in the MOW transmission spectrum induced by coating are measured and analyzed. The proposed technique of MOW functionalization allows one to reach novel sensing capabilities, including an increase in the effective sensing area, providing a convenient scaffold for the attachment of long molecules such as proteins [59], and combining in-fiber liquid sensing [60-62] and high-performance liquid chromatography [63]. The surfaces, which are covered with closely packed spherical particles, can also serve as promising sensitive elements of gas sensors [64] due to capillary condensation in the gap formed with particles in contact [65-70].

\section{Materials and Methods}

\subsection{MOW Samples and $\mathrm{SiO}_{2}$ Particles}

We use the MOW containing three concentric capillary layers surrounding the central hollow core (Figure 1a) [71]. The wall thickness for the capillaries of the first layer is $1.76 \mu \mathrm{m}$. Supermonodisperse silica nanoparticles were prepared by using the multistep method described in Reference [54] (Figure $1 \mathrm{~b}-\mathrm{d}$ ). Briefly, for the synthesis of initial 24-nm silica seeds, $9.1 \mathrm{mg}$ of L-arginine was added to $6.9 \mathrm{~mL}$ of water under magnetic stirring. Further, $0.55 \mathrm{~mL}$ of tetraethyl orthosilicate (TEOS) was slowly added, and the mixture was allowed to react for $20 \mathrm{~h}$ at $60^{\circ} \mathrm{C}$. For the synthesis of $45-\mathrm{nm}$ and $68-\mathrm{nm}$ silica seeds, we used a similar regrowth process, which was repeated twice. Final silica nanoparticles were regrown to a desirable size according to the modified Stöber process by varying the volume of TEOS and keeping the constant ratio between the reagent volumes: ethanol/water/ammonia/ $68 \mathrm{~nm}$ seeds $=18: 2: 1: 1$. For example, for the preparation of 300-nm silica nanoparticles, $7.6 \mathrm{~mL}$ of aqua ammonia was mixed with $136.8 \mathrm{~mL}$ of absolute ethanol and $15.2 \mathrm{~mL}$ of water under magnetic stirring 
at room temperature; this was followed by the addition of $7.6 \mathrm{~mL}$ of $68-\mathrm{nm}$ silica seeds. At the end, $15 \mathrm{~mL}$ of TEOS was added over $5 \mathrm{~h}$ by using a syringe pump. Finally, nanoparticles were centrifuged twice at $3000 \mathrm{~g}$ during $30 \mathrm{~min}$ and resuspended in water. The final concentration for all samples of the silica particles was equal to $12.8 \mathrm{mg} / \mathrm{mL}$.
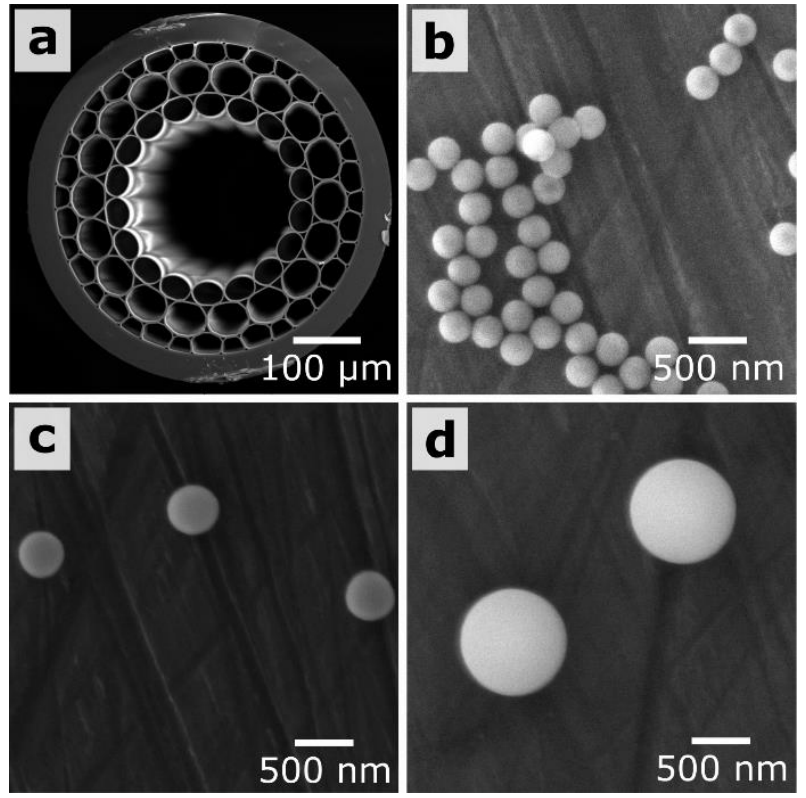

Figure 1. (a) Micrographs of scanning electronic microscopy (SEM) (Tescan, Bruno, Czech Republic) for the unfilled microstructured optical waveguides (MOW) end face with a hollow core region of $240 \mu \mathrm{m}$ and (b-d) $\mathrm{SiO}_{2}$ spherical particles with diameters of $300 \mathrm{~nm}, 420 \mathrm{~nm}$ and $900 \mathrm{~nm}$, respectively.

Poly(diallyldimethylammonium chloride) (PDDA, MW =400,000-500,000), poly(styrenesulfonate) (PSS, MW = 70,000) and polyethylenimine (PEI, MW = 2,000,000) were purchased from Sigma Aldrich (St. Louis, MO, USA). Deionized water was produced by Millipore Milli-Q Plus 185 (Merk, Darmstadt, Germany).

\subsection{Deposition Process}

We use $6 \mathrm{~cm}$-long MOW samples connected to the Shenchen peristaltic pump by a flexible silicon tube with an inner diameter of $1 \mathrm{~mm}$. To fix the samples inside the tubes, we produced special three-dimensional (3D) printed clamps, which ensured the efficient flow of solution through the samples. Our system supplies a highly controllable and persistent flow rate for any given solution capacity, allowing the uniform deposition of polyelectrolyte layers inside the capillaries (Figure 2).

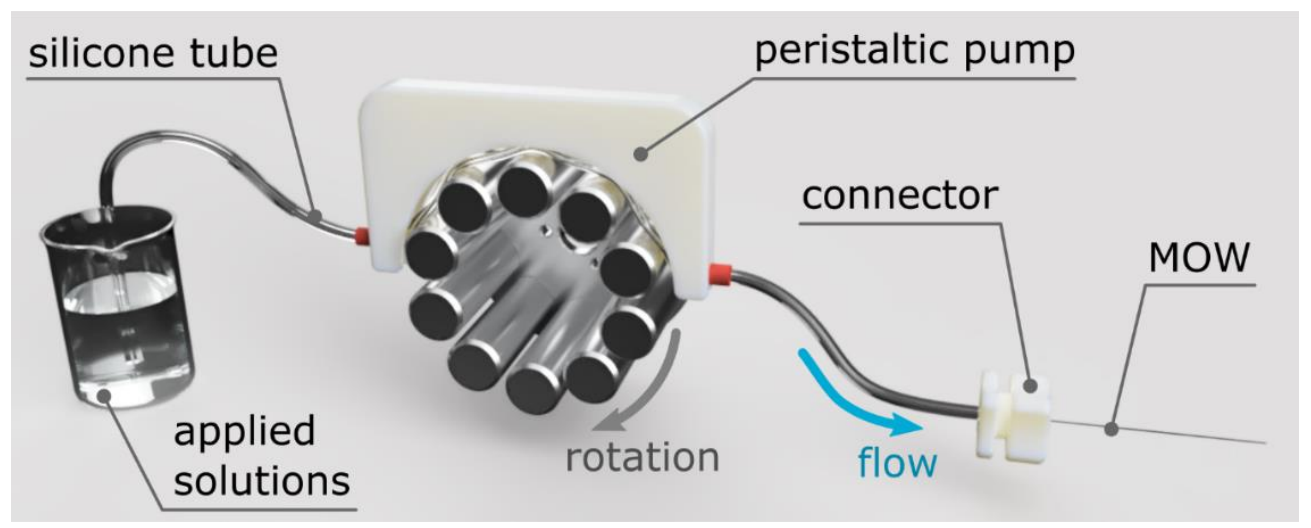

Figure 2. Schematic of the experimental setup for fiber coating. 
In the beginning, MOW samples were washed with deionized water for 5 min with a speed of $500 \mu \mathrm{L} / \mathrm{min}$ to clean them from small dust particles; then, they were immersed with the LBL technique by a combination of oppositely charged polyelectrolytes (PEI/PSS/PDDA) with a concentration of $2 \mathrm{mg} / \mathrm{mL}$ in $0.15 \mathrm{M}$ of water solution of $\mathrm{NaCl}$ during the $7 \mathrm{~min}$ for each layer; the pump flow rate was reduced to $100 \mu \mathrm{L} / \mathrm{min}$. Deionized water was applied after each polyelectrolyte layer to wash the samples and remove unadsorbed particles. At the end, we deposited the combination of five polyelectrolyte bilayers of PSS/PDDA on the inner walls of HC-MOW (the very first layer consisted of three polyelectrolytes: PEI/PSS/PDDA), which served as a substrate (buffer layer) for the stronger adhesion of the silica particles. The more polyelectrolyte layer thickness, the greater the number of $\mathrm{SiO}_{2}$ particles that adsorbed onto it through the dipper penetration into the formed polyelectrolyte substrate layer that prevents the removal of silica particles while washing MOW samples.

The possibility of the deposition of multiple silica layers was showed for 300-nm $\mathrm{SiO}_{2}$ particles. One, two, and three layers of silica particles were applied on the polyelectrolyte substrate. The effect of the polyelectrolyte intermediate coating on 300-nm silica particles deposition was investigated on the example of comparison of a single PDDA layer and PDDA/PSS/PDDA triple-layer applied between silica layers.

\subsection{Optical Characterization}

Optical measurements of MOW samples were performed by the transmission setup based on a Thorlabs CCS200 spectrometer (Thorlabs, Newton, NJ, USA) and a broadband light source: a Thorlabs SLS201L halogen lamp. The incident light was launched into a MOW sample by the $4 \times$ Olympus objective (Olympus, Tokyo, Japan), and the output signal was collected by the $10 \times$ Olympus objective, and then sent to a spectrometer for spectral analysis (Figure 3). Smooth function was applied to the measured transmission spectra. The spectra before and after the application of the smooth function were presented in Figure A1 in the Appendix A.

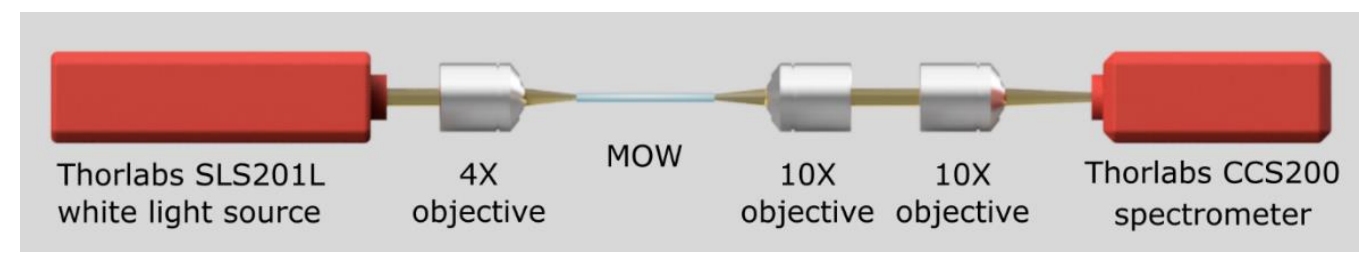

Figure 3. Schematics of the transmission measurement setup.

\subsection{Scanning Electron Microscopy}

Scanning electron microscopy (SEM) analysis was carried out with a MIRA II LMU instrument (Tescan, Brno, Czech Republic). Before imaging, the samples were coated with an about 5-nm-thick Au $1 \mathrm{~m}$ by using an Emitech K350 sputter coater. Images were taken at $30 \mathrm{kV}$.

\section{Results and Discussion}

\subsection{Polyelectrolyte Buffer Layer Deposition}

LBL deposition is based on the alternative adsorption of oppositely charged polyelectrolytes. The very first layer includes three polyelectrolytes: PEI/PSS/PDDA. Then, four PSS/PDDA bilayers were applied to finalize the formation of the buffer layer, which is aimed at strong adhesion for $\mathrm{SiO}_{2}$ particles. Figure 1 shows the resulted $\mathrm{SiO}_{2}$ particles with diameters of $300 \mathrm{~nm}, 420 \mathrm{~nm}$, and $900 \mathrm{~nm}$, and the MOW end face. Following References [72-79], we can assume that the total thickness for this buffer layer consisting of five PSS/PDDA bilayers was $30 \mathrm{~nm}$ ( $3 \mathrm{~nm}$ per a single polyelectrolyte layer). The deposited silica particles are strongly attached to capillary walls covered by such a thick substrate layer. They are not removed by the fast water flow and stayed inside even after MOWs washing with a flow rate of $7 \mathrm{~mL} / \mathrm{min}$ (the maximal value available for our microfluidic pump shown in Figure 2). 
The transmission spectra of the resulted MOW sample are shown in Figure 4. The light guiding mechanism in this type of MOW can be described via Fabry-Perot resonances [38,79], and the condition corresponding to the maximal decoupling of the core and cladding modes can be written as follows:

$$
\lambda_{j}=\frac{4 \mathrm{n}_{1} d}{2 \mathrm{j}+1}\left(\frac{n_{2}^{2}}{n_{1}^{2}}-1\right)^{1 / 2},
$$

where $j$ is an integer $(j=0,1,2 \ldots)$, describing the mode order, $n_{1}$ is the refractive index of a medium filling the capillaries (which is air in our case), $n_{2}$ is the refractive index of the fiber glass, and $d$ denotes the wall thickness for the first capillary layer. However, we notice that this model has restrictions. Specifically, it cannot provide the correct quantitative description for fiber losses and modal content away from Fabry-Perot resonances. Therefore, in the cases when these properties are relevant, the inhibited coupling model is more preferable [80].

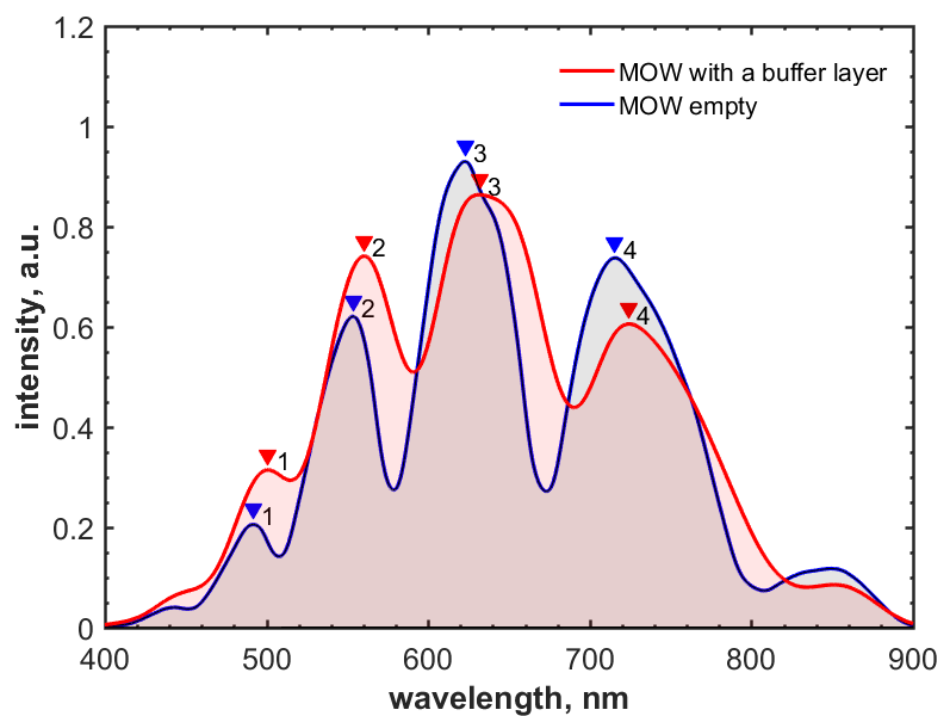

Figure 4. Spectral shifts of local transmission bands induced by poly(styrenesulfonate)/poly(diallyl dimethylammonium chloride) (PSS/PDDA) polyelectrolyte layers. Transmission spectra for the empty (uncoated) MOW (blue) and the MOWs coated with the buffer layer (red).

Equation (1) gives the local bands of the transmission shown in Figure 4 for $j=5,6,7,8$. The red-shift of the local transmission bands is caused by the effective increase in $d$ owing to the buffer layer (the difference in the refractive indexes of the fiber glass and polymers is negligible $[57,58,81,82]$ ). Table 1 shows excellent agreement between local band spectral shifts that are measured and predicted by Equation (1), for a total polyelectrolyte layer thickness of $30 \mathrm{~nm}$.

Table 1. Spectral shift of local transmission bands for MOW samples modified by PSS/PDDA layers.

\begin{tabular}{ccc}
\hline Band Number & $\begin{array}{c}\text { Spectral Shift, nm } \\
\text { Measured }\end{array}$ & $\begin{array}{c}\text { Spectral Shift, nm } \\
\text { Calculated }\end{array}$ \\
\hline Peak1 & $9 \pm 2$ & 8 \\
Peak2 & $10 \pm 2$ & 9 \\
Peak3 & $11 \pm 2$ & 11 \\
Peak4 & $11 \pm 2$ & 13 \\
\hline
\end{tabular}

\subsection{Comparison of 300-nm and 420-nm Silica Particles Coating}

Next, we consider MOW samples with a deposited layer of 300-nm and 420-nm silica particles, as presented in Figure 5. Importantly, in both cases, the nanoparticles homogeneously cover almost the 
full surface of the core capillary, which proves our concept of the polyelectrolyte buffer layer formation for the better adsorption of $\mathrm{SiO}_{2}$ nanoparticles.
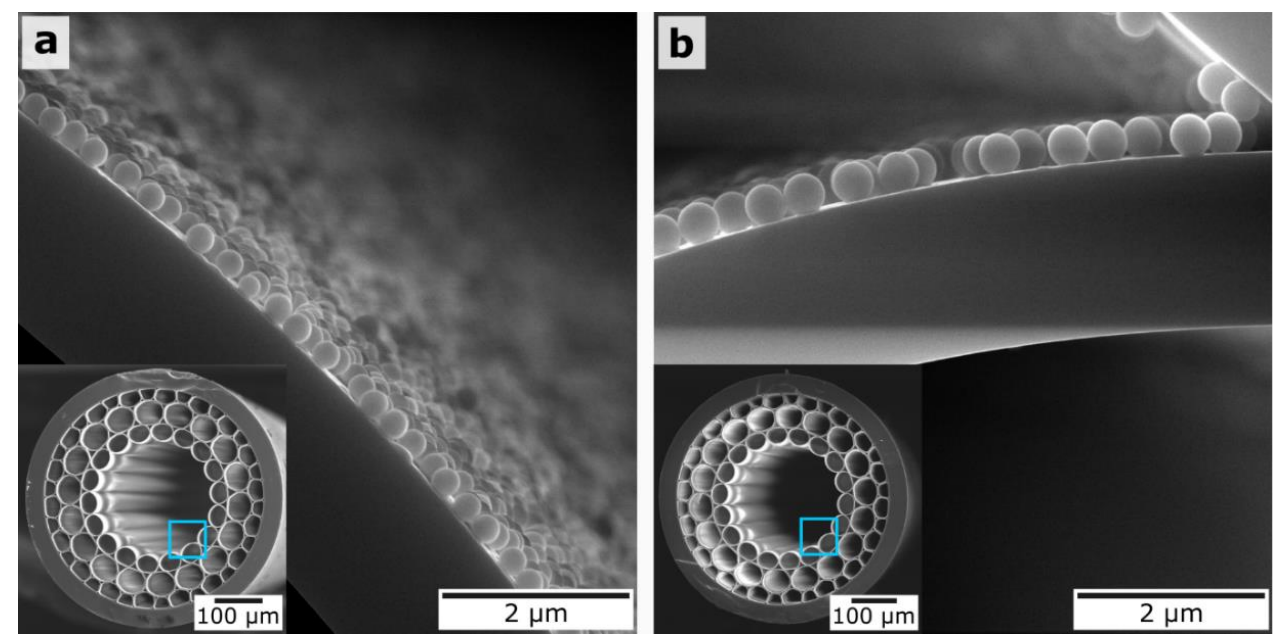

Figure 5. SEM images of MOW end faces and magnified capillary surfaces. (a) MOW sample after deposition of one layer of 300-nm silica particles. (b) MOW sample after deposition of one layer of 420-nm silica particles.

Figure 6 exhibits the transmission spectra of MOWs coated with the buffer layer only and 300-nm and 420-nm silica nanoparticles. The deposition time and flow rate were equal for $\mathrm{SiO}_{2}$ particles of both sizes. Experimentally measured spectral shifts are in good agreement with the ones calculated from Equation (1) for the deposition of 300-nm and 420-nm silica particles, and the effective thickness of applied layers of $106 \mathrm{~nm}$ and $125 \mathrm{~nm}$, respectively (Table 2).

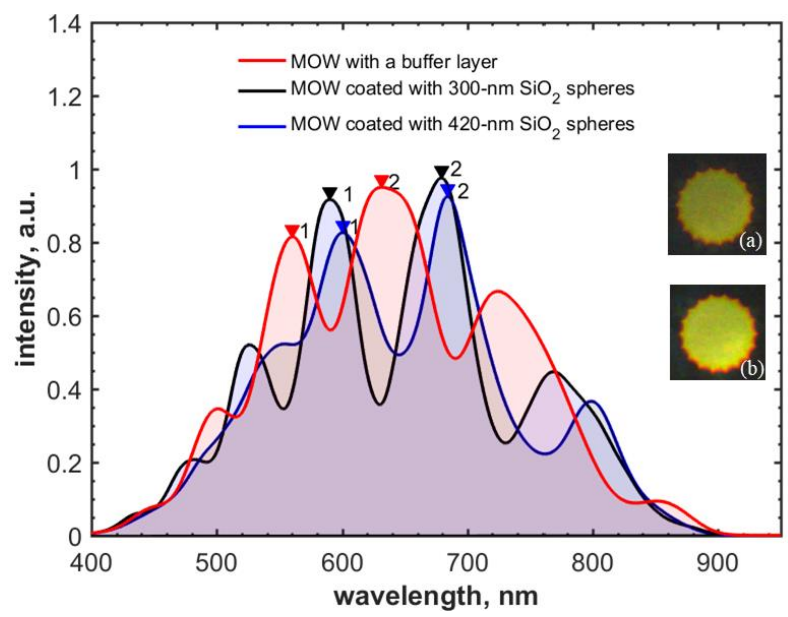

Figure 6. Spectral shift of local transmission bands for MOW samples with one deposited layer of 300-nm and 420-nm $\mathrm{SiO}_{2}$ particles into MOWs with an internal buffer layer. Inserts are the mode profiles of MOW samples modified by (a) 300-nm and (b) 420-nm silica particles.

Table 2. Transmission peaks shift of MOWs with a single layer of 300-nm and 420-nm $\mathrm{SiO}_{2}$ particles.

\begin{tabular}{|c|c|c|c|c|}
\hline \multicolumn{3}{|c|}{ Spectral Shift Measured, nm } & \multicolumn{2}{|c|}{ Spectral Shift Calculated, $\mathrm{nm}$} \\
\hline Peak number & 300-nm $\mathrm{SiO}_{2}$ & $420-\mathrm{nm} \mathrm{SiO}_{2}$ & 300-nm $\mathrm{SiO}_{2}$ & $420-\mathrm{nm} \mathrm{SiO}_{2}$ \\
\hline peak1 & $31 \pm 2$ & $38 \pm 2$ & 33 & 39 \\
\hline peak2 & $39 \pm 2$ & $45 \pm 2$ & 38 & 45 \\
\hline
\end{tabular}


From SEM images of MOWs covered by 300-nm and 420-nm silica particles (Figure 5), one can see that the capillaries became almost fully coated by $\mathrm{SiO}_{2}$ particles, regardless of the total amount of $300-\mathrm{nm}$ silica particles being greater than the $420-\mathrm{nm}$ ones at the same volume of applied solution that came from different mass of 300-nm and 420-nm silica particles. Based on this, it can be concluded that the use of $\mathrm{SiO}_{2}$ particles with a concentration of $12.8 \mathrm{mg} / \mathrm{mL}$ corresponds to a case of excess concentration for their deposition on $6 \mathrm{~cm}$-long MOW samples, and the reason of the larger spectral shift induced by the coating of $420-\mathrm{nm} \mathrm{SiO}_{2}$ particles is the larger effective thickness of the formed silica layer inside the MOW HC region than the layer thickness built from 300-nm silica particles.

\subsection{0-nm Silica Particles Deposition}

It is instructive to note that the further growth of silica nanoparticle size leads to the deterioration of the shape of the MOW transmission curve as a result of strong light scattering. For example, we covered MOW by a suspension of 900-nm silica nanoparticles (Figure 7), which led to the significant deformation of the spectral curve (Figure 8) [83].
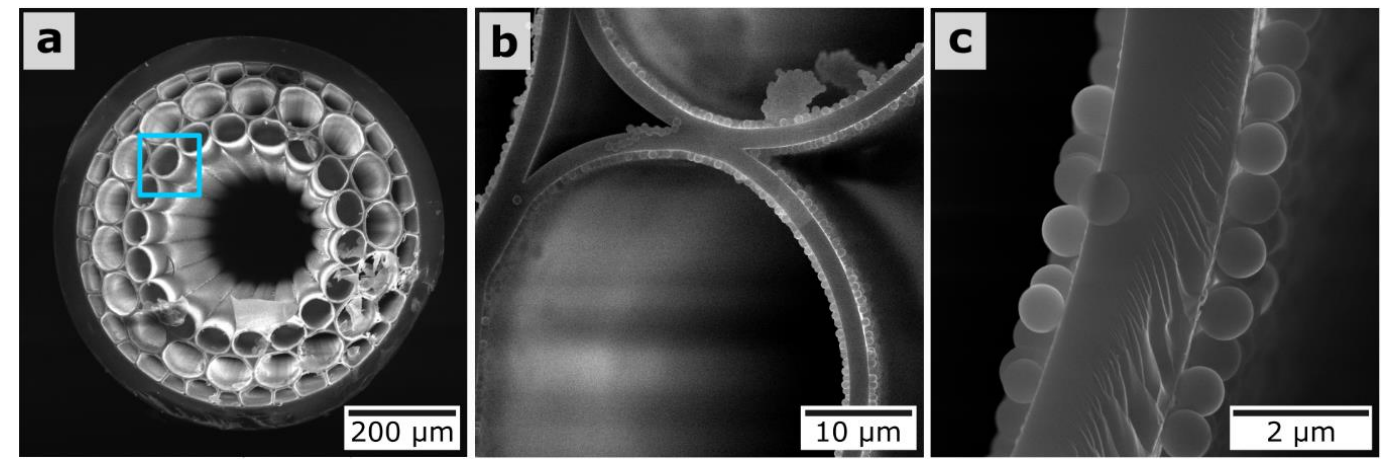

Figure 7. SEM images of $(\mathbf{a})$ the MOW end face and $(\mathbf{b}, \mathbf{c})$ capillaries with a layer of $900-\mathrm{nm}$ silica particles.

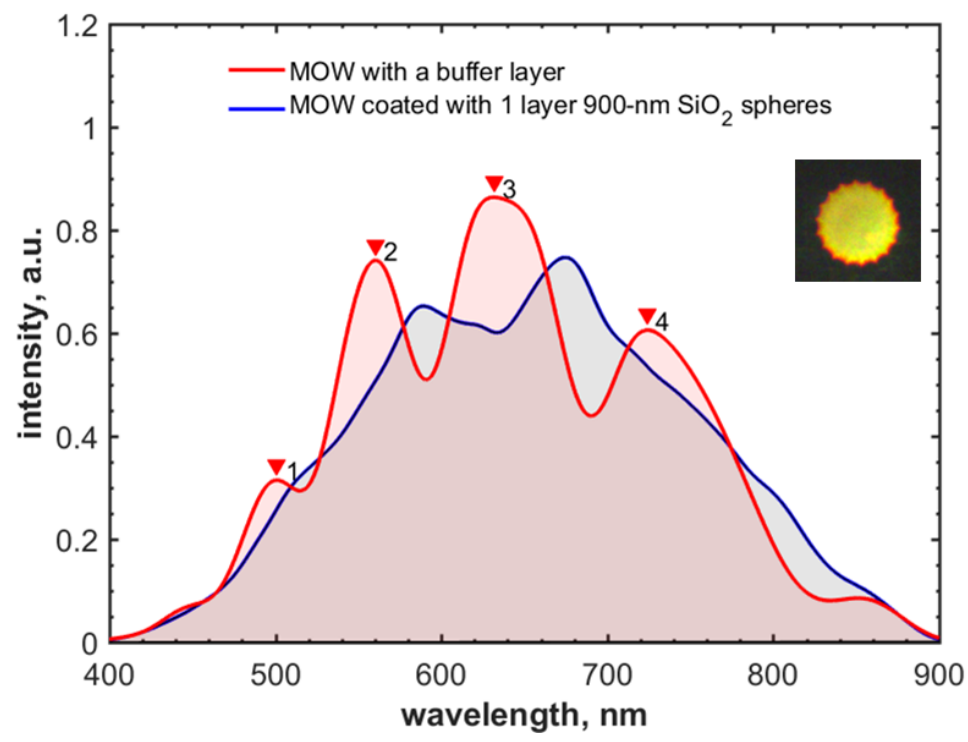

Figure 8. Transmission spectrum of MOW sample with one deposited layer of 900-nm silica particles (blue). MOW spectrum with a buffer layer (red). Insert shows the mode profile of the MOW coated with 900-nm silica particles.

To show the effect of the particle size on the transmission of MOWs, we measured an output power of MOW samples coated by one layer of silica particles with diameters of $300 \mathrm{~nm}, 420 \mathrm{~nm}$, and $900 \mathrm{~nm}$. The coupling conditions were the same (input power $19 \mu \mathrm{W}$ ). As expected, the transmitted power was 
decreasing as the particle size growths: $3.4 \mu \mathrm{W}$ for 300-nm particles, $1.9 \mu \mathrm{W}$ for $420-\mathrm{nm}$ particles, and $1.2 \mu \mathrm{W}$ for $900-\mathrm{nm}$ silica particles.

\subsection{Fluid Dynamics Inside the Capillaries}

The particle concentration in the coating layer is similar to previous cases. However, in contrast to smaller particles of $300 \mathrm{~nm}$ and $420 \mathrm{~nm}$, the bigger silica particles of $900 \mathrm{~nm}$ form layers on both sides of the capillary. This can be explained by Stoke's law and Bernoulli's principle. The viscosity force F, which describes the flow of particles inside the capillaries, is proportional to their size and velocity:

$$
\mathbf{F}=6 \pi \mu R v,
$$

where $\mu$ is the dynamic viscosity, $\mathrm{R}$ is particle radius, $v$ is the flow velocity.

Bernoulli's principle, which describes the volumetric flow rate, says that the fluid (particle suspension) inside the smaller capillaries will travel faster than the ones inside the bigger capillaries (Figure 9):

$$
\mathrm{Q}=\mathrm{A}_{1} \boldsymbol{v}_{1}=\mathrm{A}_{2} \boldsymbol{v}_{2}
$$

where $\mathrm{Q}$ is the volumetric flow rate, $\mathrm{A}_{1}$ and $\mathrm{A}_{2}$ are the cross-sections of bigger and smaller capillaries, and $v_{1}$ and $v_{2}$ are the flow velocities inside the bigger and smaller capillaries, respectively.

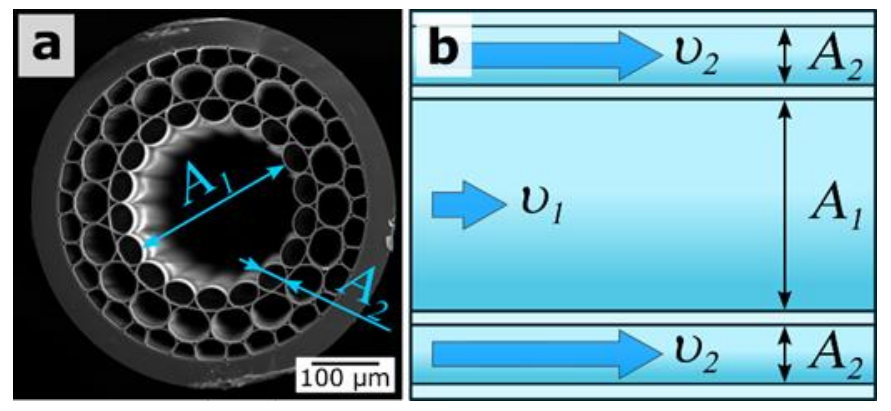

Figure 9. (a) SEM image of the MOW end face and (b) a schematic view of hollow core region surrounded by the smaller capillaries in the course of particle suspension deposition, $\mathrm{A}_{1}$ and $\mathrm{A}_{2}$ are the cross-sections of bigger and smaller capillaries, and $v_{1}$ and $v_{2}$ are the flow velocities inside the bigger and smaller capillaries, respectively.

The bigger silica particles are affected by the stronger viscosity force (Equation (2)), leading to slowing them down and, as a result, there being a higher chance of their adsorption onto capillary walls. Different local flow velocities inside large and small capillaries have the same effect on the deposition of particles (Equations (2) and (3)). The probability of particle adsorption onto the inner central hollow core surface is higher in comparison with the surrounded capillaries where the particles move faster (Equation (3)). This is well-illustrated by the strong difference between the deposition of small (300-nm and 420-nm) and large (900-nm) silica particles. In the first case, particles adhere onto the internal surface of the central capillary only; in the second, particles additionally adsorb to the first layer of capillaries (Figure 7). Such double coating results in the disappearance of the Fabry-Perot anti-resonances, which are associated with local bands in the transmission spectra (Figure 8).

\subsection{0-nm Silica Particles Multiple Layers Coating}

Next, we analyze MOW coating with three layers of 300-nm silica nanoparticles (Figure 10). It should be noted that silica particle adsorption to a buffer polyelectrolyte layer is more efficient than the deposition of the second and the third $\mathrm{SiO}_{2}$ particle layers. An intermediate PDDA layer applied between silica particles serves as a recharger and aims at their better adsorption. However, due to its small thickness (in the range of $3 \mathrm{~nm}$ ) [72-79], a lower number of silica particles are adsorbed. 
This effect is illustrated in Figure 11, where the highest spectral shift was measured for the first layer of deposited silica particles (Table 3).
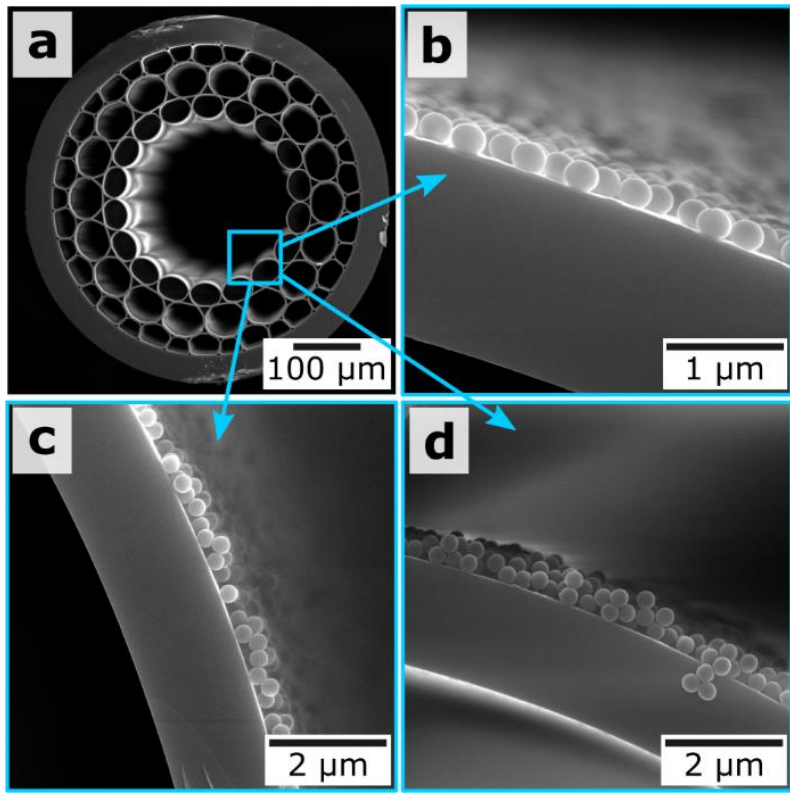

Figure 10. (a) SEM image of the MOW end face; (b-d) magnified SEM images of the capillaries with one, two, and three deposited layers of 300-nm silica particles, respectively.

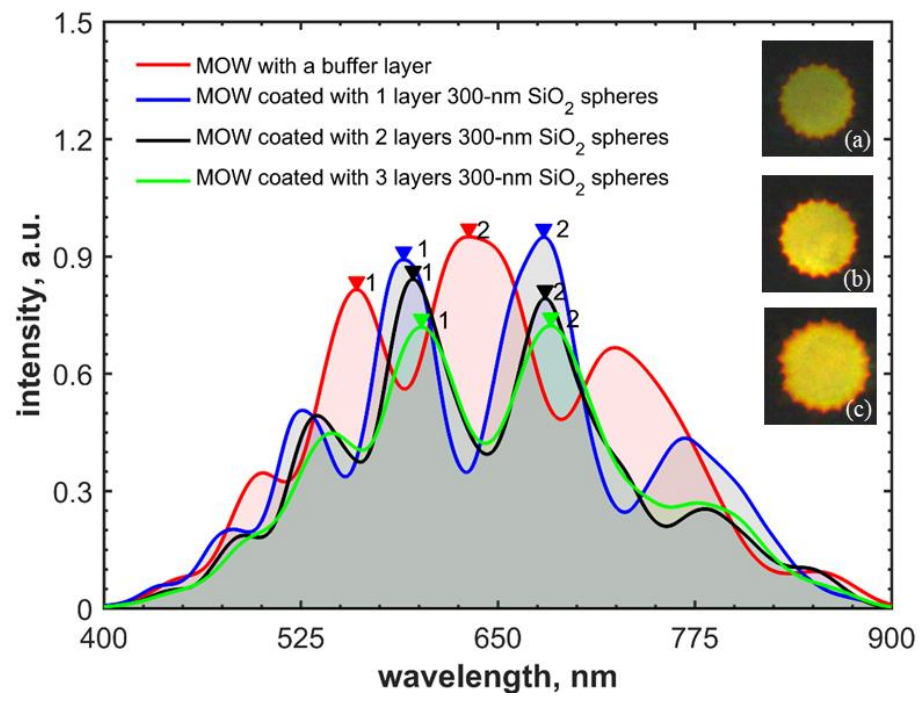

Figure 11. Transmission spectra for MOWs coated with the buffer layer only (red) and with one (blue), two (black), and three (green) layers of $300-\mathrm{nm} \mathrm{SiO}_{2}$ particles. Inserts are the mode profiles of MOWs with one (a), two (b), and three (c) layers of 300-nm silica particles.

Table 3. Shifts of the transmission peaks for MOWs driven by layers of 300-nm silica particles.

\begin{tabular}{cccc}
\hline \multicolumn{4}{c}{ Spectral Shift, $\mathbf{n m}$} \\
\hline Band number & 1 layer & 2 layers & 3 layers \\
peak1 & $31 \pm 2$ & $37 \pm 2$ & $42 \pm 2$ \\
peak2 & $39 \pm 2$ & $42 \pm 2$ & $46 \pm 2$ \\
\hline
\end{tabular}

It was established that the local transmission bands of the MOW sample with one deposited layer of 420-nm silica particles and the sample with two deposited layers of 300-nm particles were equally 
shifted because the product of the effective thicknesses and the refractive index of such formed silica layers were the same.

\subsection{Intermediate Polyelectrolyte Layer Effect on Silica Particles Adsorption}

To increase the concentration of adsorbed silica particles for multilayer deposition, we studied the effect of intermediate polyelectrolyte layers and compared the two cases: a single PDDA layer and a combination of PDDA/PSS/PDDA applied between $\mathrm{SiO}_{2}$ particles. The triple polyelectrolyte layer was chosen to form the necessary thickness for better silica particle adsorption. The higher concentration of $\mathrm{SiO}_{2}$ particles deposited on the core surface is shown in Figure 12, and the higher spectral shifts are illustrated in Figure 13 and Table 4 for two deposited layers of 300-nm silica particles.
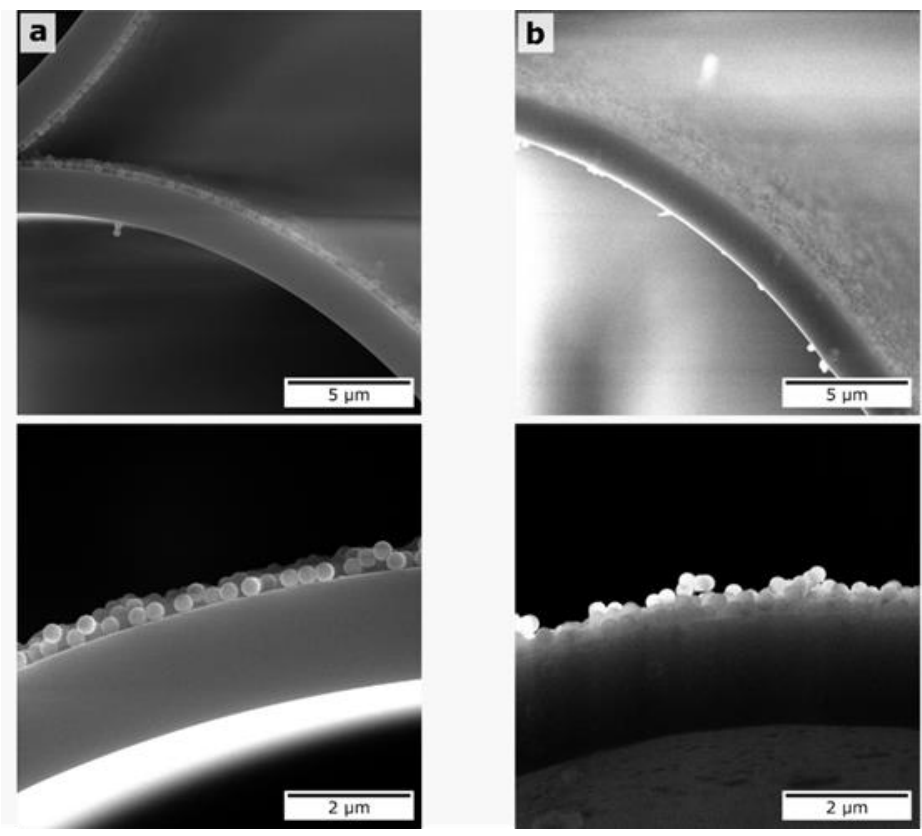

Figure 12. SEM images of $\mathrm{MOW}$ capillaries with two layers of $300-\mathrm{nm} \mathrm{SiO}_{2}$ nanoparticles for the cases of (a) PDDA/PSS/PDDA and (b) PDDA intermediate layers, respectively.

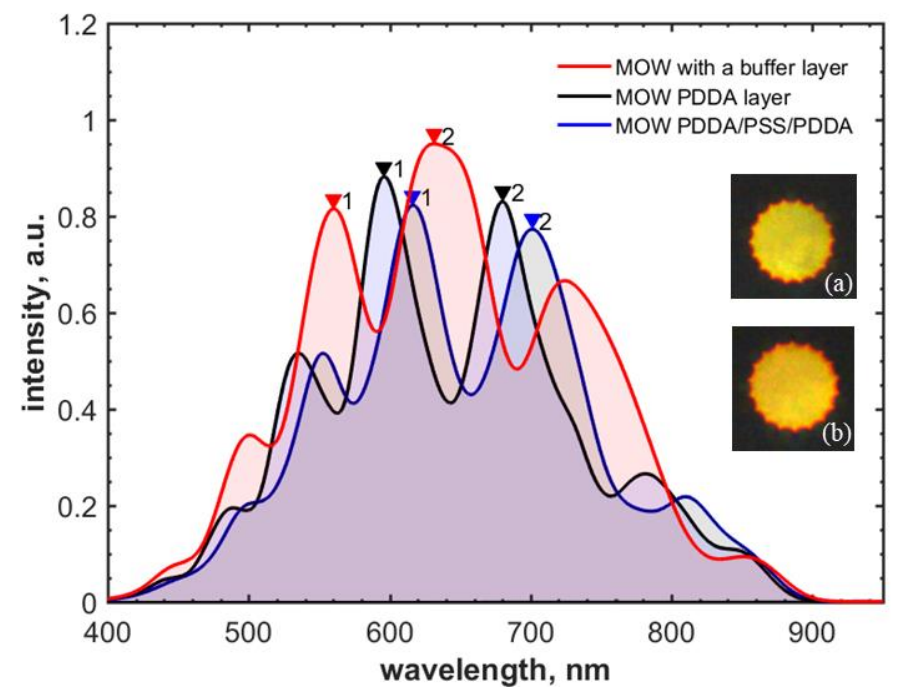

Figure 13. Transmission spectra for MOWs coated with the buffer layer only (red) and with two layers of 300-nm silica particles over PDDA (black) and PDDA/PSS/PDDA (blue) intermediate layers. The inserts are the mode profiles of MOW samples modified by two layers of 300-nm silica particles over PDDA (a) and PDDA/PSS/PDDA (b) intermediate layers. 
Table 4. Spectral shift of local transmission bands for two layers of 300-nm silica particles over PDDA or PDDA/PSS/PDDA intermediate layers.

\begin{tabular}{ccc}
\hline & Spectral Shift, $\mathbf{n m}$ \\
\hline Band number & PDDA & PDDA/PSS/PDDA \\
peak1 & $37 \pm 2$ & $57 \pm 2$ \\
peak2 & $42 \pm 2$ & $66 \pm 2$ \\
\hline
\end{tabular}

SEM images of MOW hollow core regions proved our concept of the formation of silica layers and showed the higher particle concentration for two deposited layers with a triple layer of PDDA/PSS/PDDA than the silica concentration with a single PDDA layer deposited (Figure 12).

\section{Conclusions}

For the first time to our knowledge, the LBL technique for MOW modification through the deposition of silica particles with different sizes $(300,420$, and $900 \mathrm{~nm})$ onto capillary surfaces has been presented. We have analyzed the effect of such functionalization on the optical transmission of MOWs and demonstrated a clear red-shift of the transmission windows, which is increased with the rise of the particles' size and the number of deposited particles layers. However, comparatively large particles of $900 \mathrm{~nm}$ deteriorate the fiber transmission windows due to the strong roughness of the coating surface and the undesirable light scattering which results.

We have also shown the fiber coating with one, two, and three layers of 300-nm silica particles. The largest spectral shift in the transmission is induced by the first deposited silica layer $(31 \mathrm{~nm}$ and $39 \mathrm{~nm}$, for the first and the second transmission bands, respectively), while additional silica layers are worse-adsorbed on the first layer of particles, resulting in the additional transmission spectral shifts (11 $\mathrm{nm}$ and $7 \mathrm{~nm})$.

The impact of the polyelectrolyte intermediate coating between the silica particle layers on their adsorption efficiency has been studied. A single PDDA layer was compared with a triplet of PDDA/PSS/PDDA. The SEM images of MOW samples coated by two silica particle layers show the higher concentration of adsorbed particles for PDDA/PSS/PDDA layers than for the case of a single PDDA layer deposition. Thus, silica particles deposition onto the formed triple-polyelectrolyte layers is more efficient.

To conclude, MOWs coated with layers of silica particles provide a convenient scaffold for the attachment of long molecules such as proteins and gas condensation. This in combination with the strong sensitivity of MOWs' transmission windows to the presence of analytes allows one to offer this type of functionalized MOW as a promising chemical and biological sensor. Specifically, this type of MOWs provides an opportunity for the static and dynamic detection of biomolecules applying the same technique as in Ref. [59], showing a selective cancer protein detection, but with an advantage of a larger effective sensing area. Beyond that, the controllable tuning of local transmittance bands and the enhancement of their contrast can be useful for laser light delivery and detection in neurophotonics for optogenetic studies and for monitoring/controlling of the blood-brain barrier by the endoscopic probe approach.

Author Contributions: T.E. performed the experiments; J.S.S., A.A.Z. and A.A.S. fabricated the MOW samples; B.N.K. synthesized the silica particles; T.E., D.A.G., R.E.N., S.V.G., J.S.S., B.N.K., P.G. and Y.V.P. worked on the analysis of the data and wrote the paper; D.A.G., J.S.S, and V.V.T. engaged in project administration and critical revising of the manuscript for important intellectual content; S.V.G. engaged in visualization and images preparation; V.A. and A.Z. acquired the SEM data; R.E.N., V.V.T. and D.A.G. supervised the projects.

Funding: This work was supported by the Russian Foundation for Basic Research (RFBR grant 18-29-08046). Valery V. Tuchin was supported by the Ministry of Education and Science of the Russian Federation (grant 17.1223.2017/AP).

Conflicts of Interest: The authors declare no conflict of interest. 


\section{Appendix A}

The procedure of graphs preparation is shown in Figure A1 on the example of the transmission spectra of a MOW sample coated with a polyelectrolyte buffer layer and the sample with one deposited layer of 300-nm silica particles. The effect of smooth function can be seen. It does not change the general trend of the curves but makes them easier to analyze and work with.

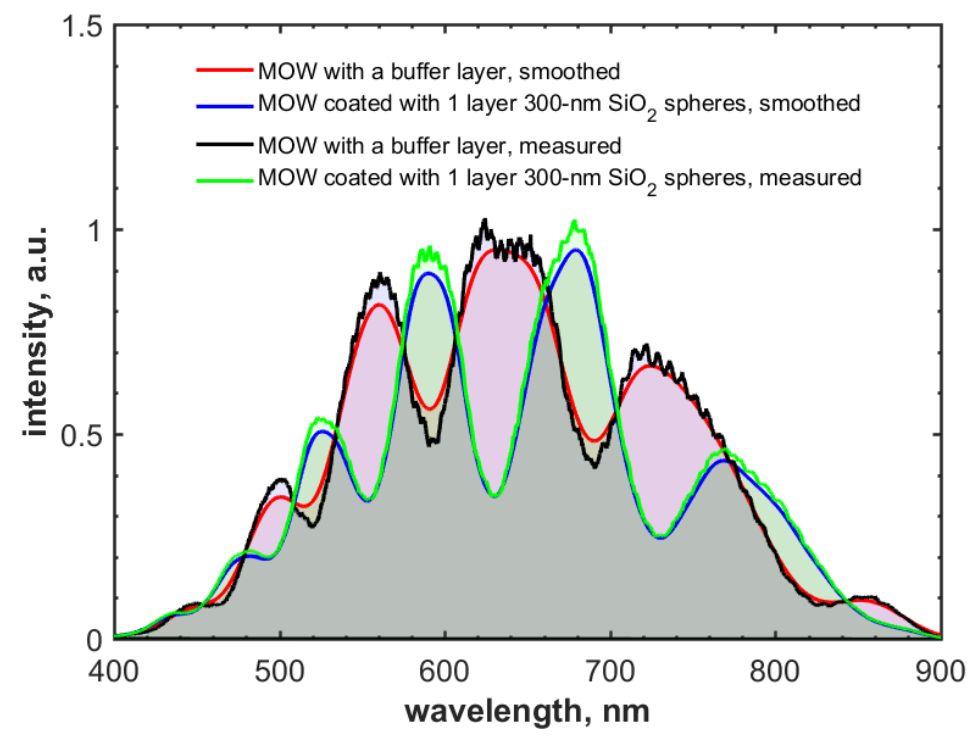

Figure A1. Transmission spectra for MOWs coated with the buffer layer only: measured (black) and smoothed (red). Transmission spectra for MOWs coated with one layer of 300-nm silica particles: measured (green) and smoothed (blue).

\section{References}

1. Knight, J.C.; Birks, T.A.; Russell, P.S.; Atkin, D.M. All-silica single-mode optical fiber with photonic crystal cladding. Opt. Lett. 1996, 21, 1547-1549. [CrossRef] [PubMed]

2. Russell, P.S.J. Photonic-Crystal Fibers. J. Lightwave Technol. 2006, 24, 4729-4749. [CrossRef]

3. Bielawny, A.; Upping, J.; Miclea, P.T.; Wehrspohn, R.B.; Rockstuhl, C.; Lederer, F.; Peters, M.; Steidl, L.; Zentel, R.; Lee, S.M.; et al. 3D photonic crystal intermediate reflector for micromorph thin-film tandem solar cell. Phys. Status Solidi A 2008, 205, 2796-2810. [CrossRef]

4. Wolfbeis, O.S. Fiber-optic chemical sensors and biosensors. Anal. Chem. 2008, 80, 4269-4283. [CrossRef]

5. Bosch, M.E.; Sanchez, A.J.R.; Rojas, F.S.; Ojeda, C.B. Recent development in optical fiber biosensors. Sensors 2007, 7, 797-859. [CrossRef]

6. Seise, B.; Csaki, A.; Schwuchow, A.; Fritzsche, W.; Weber, K.; Cialla, D.; Popp, J. Microstructured optical fibre as biosensor for pathogen detection on DNA-level. Biomed. Tech. 2012, 57, 339. [CrossRef]

7. Helmchen, F.; Fee, M.S.; Tank, D.W.; Denk, W. A miniature head-mounted two-photon microscope: High-resolution brain imaging in freely moving animals. Neuron 2001, 31, 903-912. [CrossRef]

8. Flusberg, B.A.; Lung, J.C.; Cocker, E.D.; Anderson, E.P.; Schnitzer, M.J. In vivo brain imaging using a portable 3.9 gram two-photon fluorescence microendoscope. Opt. Lett. 2005, 30, 2272-2274. [CrossRef] [PubMed]

9. Utzinger, U.; Richards-Kortum, R.R. Fiber optic probes for biomedical optical spectroscopy. J. Biomed. Opt. 2003, 8, 121-147. [CrossRef]

10. Fu, L.; Gu, M. Fibre-optic nonlinear optical microscopy and endoscopy. J. Microsc. 2007, 226, $195-206$. [CrossRef] [PubMed]

11. Fu, L.; Jain, A.; Xie, H.; Cranfield, C.; Gu, M. Nonlinear optical endoscopy based on a double-clad photonic crystal fiber and a MEMS mirror. Opt. Express 2006, 14, 1027-1032. [CrossRef]

12. Flusberg, B.A.; Cocker, E.D.; Piyawattanametha, W.; Jung, J.C.; Cheung, E.L.M.; Schnitzer, M.J. Fiber-optic fluorescence imaging. Nat. Methods 2005, 2, 941-950. [CrossRef] 
13. Gmitro, A.F.; Aziz, D. Confocal Microscopy through a Fiberoptic Imaging Bundle. Opt. Lett. 1993, 18, 565-567. [CrossRef] [PubMed]

14. Bird, D.; Gu, M. Two-photon fluorescence endoscopy with a micro-optic scanning head. Opt. Lett. 2003, 28, 1552-1554. [CrossRef] [PubMed]

15. Kasztelanic, R.; Filipkowski, A.; Anuszkiewicz, A.; Stafiej, P.; Stepniewski, G.; Pysz, D.; Krzyzak, K.; Stepien, R.; Klimczak, M.; Buczynski, R. Integrating Free-Form Nanostructured GRIN Microlenses with Single-Mode Fibers for Optofluidic Systems. Sci. Rep. 2018, 8, 5072. [CrossRef] [PubMed]

16. Ye, J.Y.; Myaing, M.T.; Thomas, T.P.; Majoros, I.; Koltyar, A.; Baker, J.R.; Wadsworth, W.J.; Bouwmans, G.; Knight, J.C.; Russell, P.S.J.; et al. Development of a double-clad photonic-crystal-fiber-based scanning microscope. In Multiphoton Microscopy in the Biomedical Sciences; International Society for Optics and Photonics: Bellingham, WA, USA, 2005; Volume 5700, pp. 23-27. [CrossRef]

17. Engelbrecht, C.J.; Johnston, R.S.; Seibel, E.J.; Helmchen, F. Ultra-compact fiber-optic two-photon microscope for functional fluorescence imaging in vivo. Opt. Express 2008, 16, 5556-5564. [CrossRef] [PubMed]

18. Monfared, A.; Blevins, N.H.; Cheung, E.L.M.; Jung, J.C.; Popelka, G.; Schnitzer, M.J. In vivo Imaging of mammalian cochlear blood flow using fluorescence microendoscopy. Otol. Neurotol. 2006, 27, 144-152. [CrossRef]

19. Heng, S.; McDevitt, C.A.; Kostecki, R.; Morey, J.R.; Eijkelkamp, B.A.; Ebendorff-Heidepriem, H.; Monro, T.M.; Abell, A.D. Microstructured Optical Fiber-based Biosensors: Reversible and Nanoliter-Scale Measurement of Zinc Ions. ACS Appl. Mater. Interfaces 2016, 8, 12727-12732. [CrossRef]

20. Doronina-Amitonova, L.V.; Fedotov, I.y.V.; Ivashkina, O.I.; Zots, M.A.; Fedotov, A.B.; Anokhin, K.V.; Zheltikov, A.M. Photonic-crystal-fiber platform for multicolor multilabel neurophotonic studies. Appl. Phys. Lett. 2011, 98, 253706. [CrossRef]

21. Doronina-Amitonova, L.V.; Fedotov, I.V.; Fedotov, A.B.; Anokhin, K.V.; Zheltikov, A.M. Neurophotonics: Optical methods to study and control the brain. Phys. Uspekhi 2015, 58, 345-364. [CrossRef]

22. Doronina-Amitonova, L.V.; Fedotov, I.V.; Ivashkina, O.I.; Zots, M.A.; Fedotov, A.B.; Anokhin, K.V.; Zheltikov, A.M. Implantable fiber-optic interface for parallel multisite long-term optical dynamic brain interrogation in freely moving mice. Sci. Rep. 2013, 3, 3265. [CrossRef] [PubMed]

23. Fedotov, I.V.; Ivashkina, O.I.; Pochechuev, M.S.; Roshchina, M.A.; Toropova, K.A.; Fedotov, A.B.; Anokhin, K.V.; Zheltikov, A.M. Quantitative cognitive-test characterization of reconnectable implantable fiber-optic neurointerfaces for optogenetic neurostimulation. J. Biophotonics 2017, 10, 1485-1491. [CrossRef] [PubMed]

24. Dufour, S.; De Koninck, Y. Optrodes for combined optogenetics and electrophysiology in live animals. Neurophotonics 2015, 2, 031205. [CrossRef] [PubMed]

25. Pisanello, F.; Mandelbaum, G.; Pisanello, M.; Oldenburg, I.A.; Sileo, L.; Markowitz, J.E.; Peterson, R.E.; Della Patria, A.; Haynes, T.M.; Emara, M.S.; et al. Dynamic illumination of spatially restricted or large brain volumes via a single tapered optical fiber. Nat. Neurosci. 2017, 20, 1180. Available online: https: //www.nature.com/articles/nn.4591\#supplementary-information (accessed on 19 June 2017). [CrossRef]

26. Chen, S.; Weitemier, A.Z.; Zeng, X.; He, L.; Wang, X.; Tao, Y.; Huang, A.J.Y.; Hashimotodani, Y.; Kano, M.; Iwasaki, H.; et al. Near-infrared deep brain stimulation via upconversion nanoparticle-mediated optogenetics. Science 2018, 359, 679. [CrossRef]

27. Euser, T.G.; Chen, J.S.Y.; Scharrer, M.; Russell, P.S.J.; Farrer, N.J.; Sadler, P.J. Quantitative broadband chemical sensing in air-suspended solid-core fibers. J. Appl. Phys. 2008, 103, 103108. [CrossRef]

28. Afshar, S.; Warren-Smith, S.C.; Monro, T.M. Enhancement of fluorescence-based sensing using microstructured optical fibres. Opt. Express 2007, 15, 17891-17901. [CrossRef]

29. Pristinski, D.; Du, H. Solid-core photonic crystal fiber as a Raman spectroscopy platform with a silica core as an internal reference. Opt. Lett. 2006, 31, 3246-3248. [CrossRef]

30. Rindorf, L.; Jensen, J.B.; Dufva, M.; Pedersen, L.H.; Hoiby, P.E.; Bang, O. Photonic crystal fiber long-period gratings for biochemical sensing. Opt. Express 2006, 14, 8224-8231. [CrossRef]

31. Rindorf, L.; Bang, O. Highly sensitive refractometer with a photonic-crystal-fiber long-period grating. Opt. Lett. 2008, 33, 563-565. [CrossRef]

32. Monzón-Hernández, D.; Minkovich, V.P.; Villatoro, J.; Kreuzer, M.P.; Badenes, G. Photonic crystal fiber microtaper supporting two selective higher-order modes with high sensitivity to gas molecules. Appl. Phys. Lett. 2008, 93, 081106. [CrossRef] 
33. Hassani, A.; Skorobogatiy, M. Design of the microstructured optical fiber-based surface plasmon resonance sensors with enhanced microfluidics. Opt. Express 2006, 14, 11616-11621. [CrossRef]

34. Gauvreau, B.; Hassani, A.; Fehri, M.F.; Kabashin, A.; Skorobogatiy, M. Photonic bandgap fiber-based surface plasmon resonance sensors. Opt. Express 2007, 15, 11413-11426. [CrossRef] [PubMed]

35. Pidenko, S.A.; Burmistrova, N.A.; Shuvalov, A.A.; Chibrova, A.A.; Skibina, Y.S.; Goryacheva, I.Y. Microstructured optical fiber-based luminescent biosensing: Is there any light at the end of the tunnel?-A review. Anal. Chim. Acta 2018, 1019, 14-24. [CrossRef]

36. Granzow, N.; Uebel, P.; Schmidt, M.A.; Tverjanovich, A.S.; Wondraczek, L.; Russell, P.S.J. Bandgap guidance in hybrid chalcogenide-silica photonic crystal fibers. Opt. Lett. 2011, 36, 2432-2434. [CrossRef]

37. Wu, D.K.C.; Kuhlmey, B.T.; Eggleton, B.J. Ultrasensitive photonic crystal fiber refractive index sensor. Opt. Lett. 2009, 34, 322-324. [CrossRef] [PubMed]

38. Zheltikov, A.M. Colors of thin films, antiresonant phenomena in optical systems, and the limiting loss of modes in hollow optical waveguides. Phys. Uspekhi 2008, 51, 591-600. [CrossRef]

39. Skibina, J.S.; Malinin, A.V.; Zanishevskaya, A.A.; Tuchin, V.V. Photonic Crystal Waveguide Sensing. Portable Biosensing Food Toxicants Environmental Pollutants; CRC Press: Boca Raton, FL, USA, 2013; pp. 1-32.

40. Frazão, O.; Santos, J.L.; Araújo, F.M.; Ferreira, L.A. Optical sensing with photonic crystal fibers. Laser Photonics Rev. 2008, 2, 449-459. [CrossRef]

41. Zhao, Y.; Lv, R.-Q.; Ying, Y.; Wang, Q. Hollow-core photonic crystal fiber Fabry-Perot sensor for magnetic field measurement based on magnetic fluid. Opt. Laser Technol. 2012, 44, 899-902. [CrossRef]

42. Wang, Y.; Yu, A.; Caruso, F. Nanoporous Polyelectrolyte Spheres Prepared by Sequentially Coating Sacrificial Mesoporous Silica Spheres. Angew. Chem. Int. Ed. 2005, 44, 2888-2892. [CrossRef]

43. Chen, X.; Randall, D.P.; Perruchot, C.; Watts, J.F.; Patten, T.E.; von Werne, T.; Armes, S.P. Synthesis and aqueous solution properties of polyelectrolyte-grafted silica particles prepared by surface-initiated atom transfer radical polymerization. J. Colloid Interface Sci. 2003, 257, 56-64. [CrossRef]

44. Caruso, F.; Lichtenfeld, H.; Giersig, M.; Möhwald, H. Electrostatic Self-Assembly of Silica Nanoparticle-Polyelectrolyte Multilayers on Polystyrene Latex Particles. J. Am. Chem. Soc. 1998, 120, 8523-8524. [CrossRef]

45. Park, M.-K.; Onishi, K.; Locklin, J.; Caruso, F.; Advincula, R.C. Self-Assembly and Characterization of Polyaniline and Sulfonated Polystyrene Multilayer-Coated Colloidal Particles and Hollow Shells. Langmuir 2003, 19, 8550-8554. [CrossRef]

46. Antipina, M.N.; Sukhorukov, G.B. Remote control over guidance and release properties of composite polyelectrolyte based capsules. Adv. Drug Deliv. Rev. 2011, 63, 716-729. [CrossRef] [PubMed]

47. Del Mercato, L.L.; Ferraro, M.M.; Baldassarre, F.; Mancarella, S.; Greco, V.; Rinaldi, R.; Leporatti, S. Biological applications of LbL multilayer capsules: From drug delivery to sensing. Adv. Colloid Interface Sci. 2014, 207, 139-154. [CrossRef]

48. Lvov, Y.; Decher, G.; Mohwald, H. Assembly, Structural Characterization, and Thermal-Behavior of Layer-by-Layer Deposited Ultrathin Films of Poly(Vinyl Sulfate) and Poly(Allylamine). Langmuir 1993, 9, 481-486. [CrossRef]

49. Ulasevich, S.A.; Brezesinski, G.; Mohwald, H.; Fratzl, P.; Schacher, F.H.; Poznyak, S.K.; Andreeva, D.V.; Skorb, E.V. Light-Induced Water Splitting Causes High-Amplitude Oscillation of pH-Sensitive Layer-by-Layer Assemblies on $\mathrm{TiO}_{2}$. Angew. Chem. Int. Ed. 2016, 55, 13001-13004. [CrossRef]

50. Skorb, E.V.; Möhwald, H.; Andreeva, D.V. How Can One Controllably Use of Natural $\Delta \mathrm{pH}$ in Polyelectrolyte Multilayers? Adv. Mater. Interfaces 2017, 4, 1600282. [CrossRef]

51. Decher, G.; Hong, J.D.; Schmitt, J. Buildup of ultrathin multilayer films by a self-assembly process: III. Consecutively alternating adsorption of anionic and cationic polyelectrolytes on charged surfaces. Thin Solid Films 1992, 210-211, 831-835. [CrossRef]

52. Iler, R.K. Multilayers of colloidal particles. J. Colloid Interface Sci. 1966, 21, 569-594. [CrossRef]

53. Grigoriev, D.; Gorin, D.; Sukhorukov, G.B.; Yashchenok, A.; Maltseva, E.; Möhwald, H. Polyelectrolyte/magnetite Nanoparticle Multilayers: Preparation and Structure Characterization. Langmuir 2007, 23, 12388-12396. [CrossRef] [PubMed]

54. Khanadeev, V.A.; Khlebtsov, B.N.; Klimova, S.A.; Tsvetkov, M.Y.; Bagratashvili, V.N.; Sukhorukov, G.B.; Khlebtsov, N.G. Large-scale high-quality 2D silica crystals: Dip-drawing formation and decoration with gold nanorods and nanospheres for SERS analysis. Nanotechnology 2014, 25, 405602. [CrossRef] [PubMed] 
55. Matsuoka, J.; Kitamura, N.; Fujinaga, S.; Kitaoka, T.; Yamashita, H. Temperature dependence of refractive index of $\mathrm{SiO}_{2}$ glass. J. Non-Cryst. Solids 1991, 135, 86-89. [CrossRef]

56. Malitson, I.H. Interspecimen Comparison of the Refractive Index of Fused Silica. J. Opt. Soc. Am. 1965, 55, $1205-1209$. [CrossRef]

57. Kang, S.; Day, D.E.; Stoffer, J.O. Measurement of the refractive index of glass fibers by the Christiansen-Shelyubskii method. J. Non-Cryst. Solids 1997, 220, 299-308. [CrossRef]

58. Tompkins, H.G.; Smith, S.; Convey, D. Optimizing the ellipsometric analysis of a transparent layer on glass. Surf. Interface Anal. 2000, 29, 845-850. [CrossRef]

59. U. S., D.; Fu, C.Y.; Soh, K.S.; Ramaswamy, B.; Kumar, A.; Olivo, M. Highly sensitive SERS detection of cancer proteins in low sample volume using hollow core photonic crystal fiber. Biosens. Bioelectron. 2012, 33, $293-298$. [CrossRef]

60. Yu, Y.; Li, X.; Hong, X.; Deng, Y.; Song, K.; Geng, Y.; Wei, H.; Tong, W. Some features of the photonic crystal fiber temperature sensor with liquid ethanol filling. Opt. Express 2010, 18, 15383-15388. [CrossRef]

61. de Matos, C.J.S.; Cordeiro, C.M.B.; Dos Santos, E.M.; Ong, J.S.K.; Bozolan, A.; Cruz, C.H.B. Liquid-core, liquid-cladding photonic crystal fibers. Opt. Express 2007, 15, 11207-11212. [CrossRef]

62. Cox, F.M.; Argyros, A.; Large, M.C.J. Liquid-filled hollow core microstructured polymer optical fiber. Opt. Express 2006, 14, 4135-4140. [CrossRef]

63. Snyder, L.R.; Kirkland, J.J.; Dolan, J.W. Introduction to Modern Liquid Chromatography; Wiley: Hoboken, NJ, USA, 2011.

64. Benabid, F.; Couny, F.; Knight, J.C.; Birks, T.A.; Russell, P.S.J. Compact, stable and efficient all-fibre gas cells using hollow-core photonic crystal fibres. Nature 2005, 434, 488-491. [CrossRef]

65. Barthelemy, P.; Ghulinyan, M.; Gaburro, Z.; Toninelli, C.; Pavesi, L.; Wiersma, D.S. Optical switching by capillary condensation. Nat. Photonics 2007, 1, 172. Available online: https://www.nature.com/articles/ nphoton.2007.24\#supplementary-information (accessed on 1 March 2017). [CrossRef]

66. Casanova, F.; Chiang, C.E.; Li, C.-P.; Roshchin, I.V.; Ruminski, A.M.; Sailor, M.J.; Schuller, I.K. Gas adsorption and capillary condensation in nanoporous alumina films. Nanotechnology 2008, 19, 315709. [CrossRef] [PubMed]

67. Evans, R.; Marconi, U.M.B.; Tarazona, P. Fluids in narrow pores: Adsorption, capillary condensation, and critical points. J. Chem. Phys. 1986, 84, 2376-2399. [CrossRef]

68. Valiullin, R.; Naumov, S.; Galvosas, P.; Kärger, J.; Woo, H.-J.; Porcheron, F.; Monson, P.A. Exploration of molecular dynamics during transient sorption of fluids in mesoporous materials. Nature 2006, 443, 965-968. [CrossRef]

69. Androutsopoulos, G.P.; Salmas, C.E. A New Model for Capillary Condensation-Evaporation Hysteresis Based on a Random Corrugated Pore Structure Concept: Prediction of Intrinsic Pore Size Distributions. 1. Model Formulation. Ind. Eng. Chem. Res. 2000, 39, 3747-3763. [CrossRef]

70. Evans, R.; Marconi, U.M.B.; Tarazona, P. Capillary condensation and adsorption in cylindrical and slit-like pores. J. Chem. Soc. Faraday Trans. 2 Mol. Chem. Phys. 1986, 82, 1763-1787. [CrossRef]

71. Skibina, J.S.; Iliew, R.; Bethge, J.; Bock, M.; Fischer, D.; Beloglasov, V.I.; Wedell, R.; Steinmeyer, G. A chirped photonic-crystal fibre. Nat. Photonics 2008, 2, 679-683. [CrossRef]

72. Ai, H.; Jones, S.A.; de Villiers, M.M.; Lvov, Y.M. Nano-encapsulation of furosemide microcrystals for controlled drug release. J. Control Release 2003, 86, 59-68. [CrossRef]

73. Ai, H.; Fang, M.; Jones, S.A.; Lvov, Y.M. Electrostatic Layer-by-Layer Nanoassembly on Biological Microtemplates: Platelets. Biomacromolecules 2002, 3, 560-564. [CrossRef]

74. Tianhong, C.; Feng, H.; Lvov, Y. FET fabricated by layer-by-layer nanoassembly. IEEE Trans. Electron Devices 2004, 51, 503-506. [CrossRef]

75. Kotov, N.A. Layer-by-layer self-assembly: The contribution of hydrophobic interactions. Nanostruct. Mater. 1999, 12, 789-796. [CrossRef]

76. Lvov, Y.; Caruso, F. Biocolloids with ordered urease multilayer shells as enzymatic reactors. Anal. Chem. 2001, 73, 4212-4217. [CrossRef]

77. Lvov, Y.M.; Kamau, G.N.; Zhou, D.L.; Rusling, J.F. Assembly of Electroactive Ordered Multilayer Films of Cobalt Phthalocyanine Tetrasulfonate and Polycations. J. Colloid Interface Sci. 1999, 212, 570-575. [CrossRef] 
78. Zhang, P.; Qian, J.; Yang, Y.; An, Q.; Liu, X.; Gui, Z. Polyelectrolyte layer-by-layer self-assembly enhanced by electric field and their multilayer membranes for separating isopropanol-water mixtures. J. Membr. Sci. 2008, 320, 73-77. [CrossRef]

79. Noskov, R.E.; Zanishevskaya, A.A.; Shuvalov, A.A.; German, S.V.; Inozemtseva, O.A.; Kochergin, T.P.; Lazareva, E.N.; Tuchin, V.V.; Ginzburg, P.; Skibina, J.S.; et al. Enabling magnetic resonance imaging of hollow-core microstructured optical fibers via nanocomposite coating. Opt. Express 2019, 27, 9868-9878. [CrossRef]

80. Argyros, A.; Leon-Saval, S.G.; Pla, J.; Docherty, A. Antiresonant reflection and inhibited coupling in hollow-core square lattice optical fibres. Opt. Express 2008, 16, 5642-5648. [CrossRef]

81. Wang, D.; He, Y.; Zhang, J.; Li, W.; Fu, X.; Tian, M.; Zhou, Y.; Yao, Z. Layer-by-layer assembled transparent polymeric adhesive films with adjustable refractive indices. Int. J. Adhes. Adhes. 2018, 85, 202-207. [CrossRef]

82. Kim, J.-H.; Hwang, J.-H.; Lim, T.-Y.J.J.C.P.R. A layer-by-layer self-assembly method for organic-inorganic hybrid multilayer thin films. J. Ceram. Process. 2009, 10, 770-773.

83. Skibina, Y.S.; Tuchin, V.V.; Beloglazov, V.I.; Shteinmaeer, G.; Betge, I.L.; Wedell, R.; Langhoff, N. Photonic crystal fibres in biomedical investigations. Quantum Electron. 2011, 41, 284-301. [CrossRef]

(C) 2019 by the authors. Licensee MDPI, Basel, Switzerland. This article is an open access article distributed under the terms and conditions of the Creative Commons Attribution (CC BY) license (http://creativecommons.org/licenses/by/4.0/). 